\title{
Dyslexia and Remediation/Education: Where Next?
}

\author{
Rhona Stainthorp
}

Published online: 4 September 2014

(C) Springer International Publishing Switzerland 2014

\begin{abstract}
Interventions to support students with reading difficulties have existed for over 70 years. This paper rehearses the need for interventions to be grounded in theory and empirical evidence about reading processes. The suggestion that the next generation of interventions should go beyond simple context-independent small unit phonics teaching to cover context-dependent larger phonological units is evaluated. Examples of contemporary interventions that involve large units, and morphology are presented. Current interventions reported target students with literacy difficulties regardless of a diagnosis of dyslexia.
\end{abstract}

Keywords Dyslexia $\cdot$ Morphology interventions $\cdot$ Reading difficulties $\cdot$ Remediation $\cdot$ Teaching interventions

\section{Introduction}

As is often the case, searches for papers reporting research into dyslexia and remediation tend to find very few papers. The term "dyslexia" always has to be broadened to identify recent studies reporting the effect of teaching programs for children with literacy difficulties. Papers discussing interventions reported here relate to participants referred to as being: lower performing; at risk (for reading difficulties); pupils who do not succeed; reading disability; low achieving; reading difficulties; and poor readers. Here is not the place to discuss what is in a name, particularly at a point when the Diagnostic and Statistical Manual of Mental Disorders (DSM-5) [1], has amended the definition of Specific Learning Disorder. The focus of the papers discussed here is on the types of

R. Stainthorp $(\bowtie)$

Institute of Education, University of Reading, 4 Redlands Road,

Reading RG1 5EX, UK

e-mail: r.w.stainthorp@reading.ac.uk interventions implemented and the impact they have on the participant learners who are in need of support to improve their literacy skills.

\section{A Possible Road Map}

A discussion paper laying out a potential road map for interventions by Compton, Miller, Elleman and Steacy [2••], is likely to become a citation classic. The paper rehearses questions about the need to have interventions that are grounded in theory, and it lays out a map for intervention research over the next decades. Compton et al., argue that existing interventions intended to help children with their reading difficulties are not designed to promote "the inductive learning mechanisms that characterize typical reading development" (p.55) [2••]. It is for this reason, they claim, that current interventions are failing to deliver the hoped for results; to help all students with reading difficulties to overcome them in a timely fashion. This is necessary if their educational and life chances are not to be compromised. For example, the evidence seems to be that between $10 \%$ and $15 \%$ of students who receive interventions to support word reading problems still have inadequate word reading skills [3]. This continues into adolescence and adulthood $[4,5]$. The limitations of word based interventions are mirrored in the results from programs designed to improve comprehension skills in reading [6,7]. These two types of intervention, word reading and reading comprehension, can be related to The Simple View of Reading [8]. In their analysis Compton, et al., [2••], conceptualize the two sets of processes highlighted in the Simple View as being partially independent. The implication of this is that interventions can be derived from theory about how we read words, how we understand texts, and the different clusters or deficits and skills found in students with reading difficulties. In their subsequent analysis they argue that current interventions target knowledge 
structures that do not support the development of generative reading skills in students with reading disability. The ultimate aim of reading is to understand the texts that are being read, and a person with reading disability may fail to comprehend texts for many reasons. For example, text comprehension is strongly correlated with word reading in the early stages of reading development [9]. This is because in the early stages word reading is likely to be effortful, slow, and not always accurate, thus making it more difficult to access the meaning locked in the print. However, as word reading becomes fluent, the correlation between this and text comprehension reduces, while that between reading comprehension and listening comprehension increases $[10,11]$. Compton, et al., [2••], argue that this partial dissociation between word reading skills and text comprehension results in different types of reading disability, which logically require different types of intervention.

One of the central arguments in the paper is that word reading interventions should be designed to support those students who have difficulties establishing fluent and accurate word reading skills. These are the people who in the past have been typically identified as having a dyslexic profile. The National Reading Panel report [12], in the USA found that there was strong evidence in favor of an initial approach to teaching word reading based on phonics, and it is this approach which has informed interventions beyond initial teaching programs. However, Compton, et al., [2••], reason that in order to become fluent word readers, students need to establish an extensive orthographic lexicon. Throughout reading development, the orthographic lexicon steadily increases. By the time they are 14 years old, typically developing students have an orthographic lexicon containing around 10,000 word specific entries [13]. This means that the next wave of interventions should be designed to support this.

Ehri [14], proposes that the orthographic lexicon develops in two ways as students learn to read. These word-specific entries - orthographic identities - are directly linked to pronunciation. In addition, there is the development of sub-word connections between orthography and phonology. These are established at the letter-phoneme level, but then further connections are established at the letter cluster level with different phonological units: namely phonemes, rimes, and syllables. Thus, through increasing exposure to print via reading, typical learners become sensitive to context-dependent relationships between orthography and phonology. They acquire these more sophisticated, context-dependent decoding rules at the subword level, in addition to their word specific knowledge, to build up a fully specified extensive lexicon. These two systems are "mutually facilitative" (p. 60) [2••], feeding off each other to ensure the establishment of an extensive lexicon and therefore an ability to read words accurately and effortlessly.

This position leads them to the speculation that people with reading disability only develop context-independent decoding rules which are not sensitive to word context and which are effortful to apply. If students with reading disability show deficits in phonological awareness, this will limit the growth in sub-word connections and potentially leave them reliant on the simple context-independent letter-phoneme connections. The "fall back" strategy then leads to an over reliance on word specific information. The impact of these two factors is that such students will not develop context-dependent, sub-word orthography-phonology connections. If they receive remediation training in context-free phonological decoding skills, the likelihood is that they will develop non-generative strategies, which are akin to letter-by-letter reading. This leads to an over-reliance on small unit mapping. There is evidence for this. Phonics instruction is helpful to get students started, but there is increasing evidence that this is not enough. They may be able to learn to use a simple decoding strategy, but this does not necessarily support the transference of the word into the orthographic lexicon $[15,16]$. Typically developing readers may be able to develop a self-teaching mechanism [17], which capitalizes on ability to be sensitive to the frequency of cooccurrences between orthographic and phonological units.

The proposal is that the next generation of remediation programs should therefore go beyond simple phonics to teach sub-word orthographic-phonological connections relating to larger units. This would require training on a large corpus of words which exemplify many aspects of orthography to phonology mapping as well as morphological mappings. This might facilitate the development of the context-dependent sub-word connections as the words are added to the orthographic lexicon.

Reading comprehension is another matter. Compton, et al., $[2 \bullet \cdot]$, feel that the current generation of interventions, designed to support those students with reading comprehension difficulties, tend not to promote deep comprehension. Interventions designed to promote reading comprehension currently tend to teach strategies to help students to engage actively with the text and to monitor their own understanding. The National Reading Report found that strategy instruction is effective. However, the reason for it being so has not yet been established. This has implications for the development of further interventions. It is not enough to know that something is effective, we need to know why. This leads Compton, et al., $[2 \bullet \cdot$, to speculate that it may not be the strategies being taught per se, but because they may incidentally lead to a deeper, more focused engagement with the text and insights about the need to monitor one's own understanding. This in itself is not a bad thing, but there is the possibility that the strategies being taught may lead to non-generative low level text representations that relate to the text being read. This would be textspecific comprehension and may not transfer to texts in general.

Students with poor reading comprehension have difficulties in going beyond the surface of the text to construct a "deeper meaning" [18]. Models of reading comprehension 
generally suggest two levels of representation; a text-based representation, and a situation model [18, 19]. Poor comprehenders tend to show no deficits when required to answer questions about the literal meaning of texts [20]. Their difficulties seem to lie in accessing background information and making inferences. They have difficult in building a situation model of a text. Additionally, poor readers tend to have less background knowledge to draw upon to build situation models, which in turn impacts on their ability to construct a situation model at all [21].

Taking this into account, Compton, et al., [2••], propose that the next generation of reading comprehension interventions should focus on three main areas. The first is called "microworld knowledge building". Through providing students with prior background knowledge about the topic in texts, they propose that inference making will be facilitated and students will thus be able to begin to build situation models about texts. This is perhaps a chancy proposal, as they acknowledge, since the evidence for building microworlds comes from limited work with computer simulations [22].

The second approach is to use latent semantic analysis (LSA) of texts as a support for general knowledge building. A result of Matthew effects in reading [23], is that poor readers have fewer reading experiences. This has a negative impact on their acquisition of world knowledge through engagement with texts, which in turn compromises their ability to comprehend texts. Given that reading comprehension difficulties tend to be identified late, the gap in world knowledge between typical readers and those with difficulties becomes problematic. Compton, et al., [2••], suggest that a fruitful approach to supporting students with comprehension difficulties is to build up their general knowledge, in order to give them the necessary database for understanding texts. They propose that LSA could be a tool for teachers to select texts to support the buildup of knowledge. This would be a more efficient and systematic way of identifying useful texts than having teachers make the selection by hand [24]. This proposal is purely speculative.

The final approach is to provide students with a program to support their capacity for making inferences. Of the three approaches this is the one that has support from empirical evidence. Poor comprehenders tend to be poor at making the inferences necessary to comprehend texts $[20,25]$. There is considerable evidence (some of it quite old now), that teaching students to make inferences, to enable them to go beyond the surface of the text to arrive at a deeper understanding, is effective across a range of ages [26-31]. Compton, et al., $[2 \bullet \bullet$, acknowledge that many of the approaches to teaching inferences involve teaching strategies per se, but they maintain that these are necessary for helping students to overcome these particular difficulties. What is new about their proposal is that they suggest inference training should be done in conjunction with explicit development of world knowledge, in order to facilitate the building of situation models.

These proposals, both in relation to word reading and comprehension, set out an agenda for the next decades and provide an excellent framework against which to judge the research reported in the last twelve months. The following papers published in 2013/2014 show that some of the approaches articulated by Compton, et al., [2••], are already permeating the research community.

\section{Phonics Training Beyond Simple Letter-Sound Correspondences}

Chen and Savage [32•], report on an intervention with at-risk readers who had generally mastered basic phonics. The intervention took phonics beyond simple letter-sound training to include complex clusters. They did not train the participants in mapping at the phonological level above the phoneme, as recommended by Compton et al., but they had a principled approach to training. Based on the work of Vousden, Ellefson, Solity and Chater [33], they selected a set of optimally efficient grapheme-phoneme correspondence (GPC) units that lead to the greatest generalisation in words. The participants $(n=38)$ were in Grades 1 and 2 in a dual French/English primary school in Quebec, Canada and randomly assigned to the intervention group or a word usage control condition. The parents reported speaking to their children in both French and English but primarily reading to them in English. The intervention and control conditions were delivered in small groups of four or five.

At the start of each session all participants took part in a spelling session where they were asked to try to spell one or two target words without any exposure to the words. They then took part in a "look-cover-write-check" procedure. The targets were left on a white board for the remainder of the session whilst the teacher read a story containing the word. At the end of this element of the program the children either took part in the GPC intervention or in the word usage control.

The intervention was one where complex graphemephoneme mappings were taught. The target GPCs were always introduced in the context of a real word, but the letters of the target were always highlighted in red whilst the other letters of the word would be in black. Instruction included information about where the GPCs were normally positioned in words, including position constraints that lead to contextdependent pronunciations. Each session included opportunities to read target words in passages from books. In the control condition, participants encountered the same words as in the intervention, but they focused on word usage. The program lasted for nine weeks and pre- and post-intervention measures of word reading, spelling, and reading motivation were taken. There were significant positive effects of receiving the 
complex GPC intervention on spelling, word reading, and reading motivation. Chen and Savage [32•], reason that their program was effective because the complex GPCs that were explicitly taught built on existing knowledge, and were maximally useful for reading the words in the texts. The impact on spelling was an important finding because the participants had only been taught unidirectional complex grapheme-phoneme knowledge. This instruction appeared to transfer to phonemegrapheme knowledge. Though the intervention did not move beyond mapping the phonemes, this result suggests that the Compton, et al., [2••], proposals are worth pursuing.

\section{Morphological Interventions}

Compton, et al., [2••], identify the potential impact on reading of developing word reading interventions which go beyond the phoneme. There are sound theoretical reasons for this. One word characteristic that they do not focus on explicitly is morphology. Morphological instruction goes beyond phonics instruction to teach students to identify and analyse the morphemes (i.e., the units of meaning), in words. This includes focusing on roots and affixes. In English, affixes have a high level of predictability and consistency in their spelling. They are also bound morphemes, so in working on affixation students can be made aware of their contextdependent nature. Morphological instruction therefore is consistent with the proposal to teach advanced decoding skills and word identification at the sub-word level. Goodwin and Ahn [34•], conducted a meta-analysis of 30 independent studies which reported on the effects of morphological interventions conducted in English and published since 1980. All studies involved students of school age, and all included a control/comparison treatment group. Their strategy included searching for dissertations as well as for published studies, because of the bias towards acceptance of studies with statistically significant effects in publishing.

The finding was that overall there were moderate positive effects of morphological instruction on the measures of word reading accuracy, morphological knowledge, phonological awareness, vocabulary, and spelling. However, there was no effect on reading comprehension or on word reading fluency. They also found that the effect sizes of training were greater the younger the participants.

Although morphological training relates to different units of language than the rime, syllable, and word level phonology discussed by Compton, et al., [2••], both in size and kind, it is not too much of a leap to see a connection between the two, since both involve contextdependent decoding.

\section{Morphological Awareness Training}

Wolter and Dilworth [35], report the findings of the effects of a multi-linguistic morphological awareness intervention on the reading and spelling of second grade pupils with spelling difficulties. Twenty students took part in the study during a summer literacy camp. The program took place over nine days with 90 minutes of daily instruction. The students were randomly assigned to one of two interventions; orthographic intervention, or morphological intervention. There were two groups for each intervention. Both groups received a common orthographic component which lasted for 45 minutes and included exposure to complex orthographic patterns. This element also included elements of reading comprehension relative to unknown words with complex orthographic patterns. The morphology group received activities which focused on morphological spelling patterns in complex words, with both derivational and inflectional affixes. This program therefore met the requirement proposed by Compton, et al., [2••], to go beyond simple letter-sound work to reflect on larger phonological units, though in this program the focus was on meaning rather than the larger phonological units per se.

The outcome of the intervention was that both groups made significant improvements overall. There were significant improvements in word reading, word attack skills, and a nonstandardized test of spelling the orthographic patterns targeted in the intervention. However, the morphology intervention group made significantly greater improvements in reading comprehension and in spelling on a non-standardized spelling test of the morphological units targeted in the intervention. Given that both groups had received the same comprehension training, it was possible for them to conclude that the morphology training provided an additional bridge to support access to meaning. However, there was a potential design flaw in the study because the orthography group received their comprehension training at the end of their sessions, whereas the morphology group received it at the beginning of theirs. Children at this age do find it difficult to concentrate for long periods of time.

\section{Morphology and Writing}

Literacy difficulties are not just manifested in reading difficulties; indeed students may struggle far more with spelling and writing as they advance in the education system. There is growing evidence about how orthography does not just reflect phonology but also the larger units of morphology. Also, there is increasing research evidence that teaching about morphology can improve spelling performance in typically developing students [36], as well as in those with dyslexia [37]. McCutchen, Stull, Herrera, Lotas and Evans [38•], report on 
the impact of a 12-week intervention involving morphology embedded within the science curriculum in mainstream classes in the USA. The study was designed to investigate whether the intervention designed for fifth-grade students improved ability to generate and spell morphologically complex words. They were particularly interested in the potential for the program to have a differential impact on the performance of poorly performing students. The program was implemented in science classes. The experimental groups $(n=95)$ received the same science teaching as the students in the no-treatment control groups $(n=75)$. The additional morphology teaching related to the multi-morphemic science vocabulary. Teaching involved scripted lessons on the morphemic nature of the vocabulary, including word and morpheme definitions in the context of spelling. Students were actively engaged in writing and spelling throughout the program. The results were encouraging. Post-test tasks or sentence combining and more extended writing showed that the intervention groups used more morphologically complex words. The poorer students showed the greatest effect of the intervention.

\section{Syllable Training}

Compton, et al., [2••], very explicitly took an "Englishcentric" (p.59) approach to their analysis. English orthography does pose significant challenges to learners, and the evidence seems to be that it is harder to learn than other alphabetic European languages [39]. Nevertheless, there are students who have reading difficulties in all orthographies. This means that the analysis of potential future interventions could inform work across languages. Heikkilä, Aro, Närhi, Westerholm and Ahonen [40•], report the impact of an intervention in Finland which focused on syllabic units. Finnish has a transparent orthography but the spoken language is very different from English. Its agglutinative nature results in many very long multi-syllabic/multi-affixed words. They reasoned that training in syllables would enable the students to extract and utilise units larger than the phoneme (c.f., Compton, et al. [2••]), and would be particularly beneficial for Finnish readers. The training was implemented through ten computer training sessions. Students heard 30 syllables presented randomly over headphones and then had to choose the correct written stimulus as quickly as possible from five options on the screen. The stimuli varied in length (two-, or four-letter syllables), and frequency. The participants were nine year old students who were only receiving part-time education because of their literacy difficulties. There were three different intervention groups. One group were trained on two letter syllables $(n=48)$; the second group was trained on four letter frequent syllables $(\mathrm{n}=30)$; and the third group was trained on four letter infrequent syllables $(n=37)$. There was an additional treated control group who received maths tasks which did not require reading $(\mathrm{n}=35)$. The training had significant positive effects on reading speed, indicating that students were becoming more fluent. The effects were most marked with the longer more infrequent syllables. However, the effects were confined to the trained syllables and did not transfer to other syllables, or to texts which only included few of the training syllables. The intervention showed promise as a strategy for repeated focused exposure to orthography. However, the lack of transfer to other than trained items was problematic if considered in the light of the Compton, et al., [2••], analysis. The students did not seem to extract usable information beyond the training sets. The authors speculate that this lack of transfer might have resulted from the fact that training was conducted using computer generated stimuli, but outcome measures were related to reading texts aloud.

\section{Conclusion}

Interventions for students with literacy learning difficulties have a long and chequered history. For example, the OrtonGillingham program Remedial Training for Children with Specific Disability in Reading, Spelling and Penmanship was first published in 1935, and is still in use today. However, we have moved beyond programs based on rhetoric to an approach that sees interventions arising from established theory and empirical evidence. The interventions reported on here provide an indication that theory and empirical evidence from research have informed the shaping of recent programs. Even where the numbers of participants are small, control groups are included. This lends weight to claims made for efficacy. If children with reading difficulties are to be well served by the education system, they need programs which work. The road map laid out by Compton, et al., [2••], has the potential to lead to a new generation of theoretically sound evidence-based interventions. The current work on morphology and word reading strategies beyond simple phonics is encouraging. However, there seems to be less work aimed at supporting students with difficulties beyond the level of the word.

\section{Compliance with Ethics Guidelines}

Conflict of Interest Rhona Stainthorp declares that she has no conflict of interest.

Human and Animal Rights and Informed Consent This article does not contain any studies with human or animal subjects performed by any of the authors. 


\section{References}

Papers of particular interest, published recently, have been highlighted as:

- Of importance

-. Of major importance

1. Diagnostic and Statistical Manual of Mental Disorders (DSM-5). Arlington: American Psychiatric Association; 2013.

2.• Compton DL, Miller AC, Elleman AM, Steacy LM. Have we forsaken reading theory in the name of "quick fix" interventions for children with reading disability? Sci Stud Read. 2014;18(1):5573. doi:10.1080/10888438.2013.836200. Articulates a carefully argued road map for the need to link interventions to theory. The proposed form that interventions should take has the potential to have direct impact on remediation for reading difficulties.

3. O'Connor R, Fuchs LS. Responsiveness to intervention in the elementary grades: implications for early childhood education. In: Buysse V, Peisner-Feinberg E, Cantler J, editors. Handbook of response to intervention (RTI) in early childhood education. Baltimore: Brookes; 2013. p. 41-56.

4. Barnes MA, Davis C, Priebe S, Arrington N, Francis D, Fletcher J. Word-level, text-level and general purpose cognitive skills in struggling adolescent readers: Implications for assessment and intervention. In: Lovett MW, Greenberg D (Chairs). Assessment and intervention research with struggling adolescent and adult readers. Symposium conducted at the annual meeting of the Society for the Scientific Study of Reading. Montreal, Canada; 2012.

5. Brasseur-Hock I, Hock MF, Kieffer MJ, Biancarosa G, Deshler DD. Adolescent struggling readers in urban schools: results of a latent class analysis. Learn Individ Differ. 2011;21:438-52.

6. Solis M, Ciullo S, Vaughn S, Pyle N, Hassaram B, Leroux A. Reading comprehension interventions for middle school students with learning disabilities: a synthesis of 30 years of research. J Learn Disabil. 2012;45:327-40.

7. Willingham $D$. The usefulness of brief instruction in reading comprehension strategies. Am Educ. 2006;50:39-45.

8. Hoover WA, Gough PB. The simple view of reading. Read Writ. 1990;2:127-60.

9. Rayner K, Foorman B, Perfetti CA, Pesetsky D, Seidenberg MS. How psychological science informs the teaching of reading. Psychol Sci Public Interes. 2001;2:31-74.

10. Johnston AM, Barnes MA, Desrochers A. Reading comprehension: developmental processes, individual differences, and interventions. Can Psychol Psychol Can. 2008;49:125-32.

11. Stanovich KE, Cunningham AE, Feeman DJ. Relation between early reading acquisition and word decoding with and without context: a longitudinal study of first-grade children. J Educ Psychol. 1984;76:668-77.

12. National Institute of Child Health and Human Development. Report of the National Reading Panel (NIH Publication No. 00-4754). Washington, DC: Government Printing Office; 2000.

13. Ehri LC. Learning to read words: theory, findings, and issues. Sci Stud Read. 2005;9:167-88.

14. Ehri L. Orthographic mapping in the acquisition of sight word reading, spelling memory, and vocabulary learning. Sci Stud Read. 2014;18:5-21. doi:10.1080/10888438.2013.819356.

15. Nation K, Angell P, Castles A. Orthographic learning via selfteaching in children learning to read English: effects of exposure, durability, and context. J Exp Child Psychol. 2007;96:71-84.

16. Wang H, Nickels L, Nation K, Castles A. Predictors of orthographic learning of regular and irregular words. Sci Stud Read. 2013;17: 369-84.
17. Share DL. Phonological recoding and self-teaching: Sine qua non of reading acquisition. Cognition. 1995;55:151-218.

18. Kintsch W, Rawson KA. Comprehension. In: Snowling MJ, Hulme $\mathrm{C}$, editors. The science of reading: a handbook. Oxford: Blackwell; 2005. p. 209-26.

19. Perfetti CA, Landi N, Oakhill J. The acquisition of reading comprehension skill. In: Snowling MJ, Hulme C, editors. The science of reading: a handbook. Oxford: Blackwell; 2005. p. 227-47.

20. Cain K, Oakhill JV, Barnes MA, Bryant PE. Comprehension skill, inference-making ability, and the relation to knowledge. Mem Cogn. 2001;29:850-9.

21. Kintsch W. Learning and constructivism. In: Tobias S, Duffy TM, editors. Constructivist instruction: success or failure? New York: Routledge; 2009. p. 223-41.

22. Frank SL, Koppen M, Noordman LGM, Vonk W. Modeling knowledge-based inferences in story comprehension. Cogn Sci. 2003;27:875-910.

23. Stanovich KE. Matthew effects in reading: some consequences of individual differences in the acquisition of literacy. Read Res Q. 1986;22:360-407.

24. Clinton V, van den Broek P. Interest, inferences, and learning from texts. Learn Individ Differ. 2012;22:650-63.

25. Cain K, Oakhill JV. Inference making ability and its relation to comprehension failure in young children. Read Writ. 1999;11:489 503.

26. Emery DW, Milhalevich C. Directed discussion of character perspectives. Read Res Instr. 1992;31:51-9.

27. Elbro C, Buch-Iversen I. Activation of background knowledge for inference making: effects on reading comprehension. Sci Stud Read. 2013;17:435-52.

28. Hansen J, Pearson DP. An instructional study: improving the inferential comprehension of good and poor fourth-grade readers. J Educ Psychol. 1983;75:821-9.

29. Spires HA, Donley J. Prior knowledge activation: inducing engagement with informational texts. J Educ Psychol. 1998;90:249-60.

30. Yuill N, Joscelyne T. Effect of organizational cues and strategies on good and poor comprehenders' story understanding. J Educ Psychol. 1988;80:152-8.

31. Yuill N, Oakhill J. Effects of inference awareness training on poor reading comprehension. Appl Cogn Psychol. 1988;2:313-45.

32. Chen V, Savage RS. Evidence for a simplicity principle: teaching common complex grapheme-to-phonemes improves reading and motivation in at-risk readers. J Res Read. 2014;37(2):196-214. doi:10.1111/1467-9817.12022. Evidence that poor readers benefit from training in more complex graphemic units.

33. Vousden JI, Ellefson MR, Solity J, Chater N. Simplifying reading: applying the simplicity principle to reading. Cogn Sci. 2011;35(1): 34-78. doi:10.1111/j.1551-6709.2010.01134.x.

34. Goodwin AP, Ahn S. A meta-analysis of morphological interventions in English: effects on literacy outcomes for school-age children. Sci Stud Read. 2013;17(4):257-85. doi:10.1080/10888438. 2012.689791. Excellent meta-analysis of existing morphological intervention studies. Provides a detailed commentary on the characteristics of studies which should inform the development of further programs.

35. Wolter JA, Dilworth V. The effects of a multilinguistic morphological awareness approach for improving language and literacy. J Learn Disabil. 2014;47:76-85. doi:10.1177/0022219413509972.

36. Nunes T, Bryant P. Improving literacy by teaching morphemes. New York: Routledge; 2006.

37. Berninger VW, Winn WD, Stock P, Abbott RD, Eschen K, Lin SJ, et al. Tier 3 specialized writing instruction for students with dyslexia. Read Writ Interdiscip J. 2008;2:95-129.

38. McCutchen D, Stull S, Herrera BL, Lotas S, Evans S. Putting words to work: effects of morphological instruction on children's writing. J Learn Disabil. 2014;47:86-97. doi:10.1177/0022219413509969. 
Provided evidence for the link between morphology and writing being an effective tool in remediation. Particularly important in linking writing to a curriculum area.

39. Seymour PHK, Aro M, Erskine JM. Foundation literacy acquisition in European orthographies. Br J Psychol. 2003;94: 143-74.
40. Heikkilä R, Aro M, Närhi V, Westerholm J, Ahonen T. Does training in syllable recognition improve reading speed? A computer-based trial with poor readers from second and third grade. Sci Stud Read. 2013;17:398-414. doi:10.1080/10888438.2012.753452. Provided some initial evidence that training in syllable awareness can improve reading speed amongst poor readers of Finnish. 